\title{
Mentoring: are you being or doing? That is the question
}

\author{
Janine Brooks ${ }^{1}$
}

\author{
Key points \\ Explores core elements of mentoring.
}

Highlights mentoring skills as intrinsic to dental practice.
Offers a reflection on mentoring as an 'add on' function.

\begin{abstract}
Mentoring is finally coming into its own. The signs are good: the General Dental Council thinks it's important; the British Dental Association thinks it's important; and the royal colleges, Health Education England and local dental committees have all stated that they support mentoring and mentors as beneficial and important. Confidence levels are rising that mentoring is something all dental professionals would benefit from. In this piece I would like to encourage all dental professionals not to view mentoring as something that needs to be an 'add on' or something extra but something that is intrinsic to what and who we are. If we can move away from 'doing' mentoring to 'being' mentors, we will all gain and all aspects of our professional life can be enriched.
\end{abstract}

\section{Introduction}

Mentoring is finally coming into its' own, at least I think and hope so. The signs are good: the General Dental Council (GDC) thinks it's important, the British Dental Association (BDA) thinks it's important, the royal colleges, Health Education England (HEE) and local dental committees (LDCs) have all stated that they support mentoring and mentors as beneficial and important. Confidence levels are rising that mentoring is something all dental professionals would benefit from. So, that's all good then!

When considering continuing professional development (CPD), the GDC noted that:

'Activities such as coaching and mentoring, where individuals are supported by other members of the dental profession, also have an important role to play here, and are valuable

'Dentalia Coaching and Training Consultancy, Park Lane Cottage, Park Lane, Watford Village, Northampton, UK. Correspondence to: Janine Brooks

Email: Janine.brooks47@gmail.com

Accepted 18 April 2019

https://doi.org/10.1038/s41415-019-0616-9 ways of enhancing the skills and approach of all involved.' ${ }^{1}$

The latest GDC guidance on undertaking enhanced CPD states:

'Your Personal Development Plan (PDP) can be created individually or in conjunction with your peers, your employer/line manager/ commissioner or your wider dental team. Many health professionals find it useful to work with a mentor to develop their learning needs, and the GDC encourages you to build this kind of relationship where possible.'2

The University of Winchester gives coaching and mentoring as the most common type of remediation support. They also comment that a number of Practitioner Advice Support Schemes (PASS) offer mentoring. HEE are included as providing coaching and mentoring as the most frequent (67.7\%) support provided for dental registrants in difficulty. ${ }^{3}$

The Royal College of Surgeons produced an excellent guide to mentoring, in which they suggest:

'Mentoring programmes provide an opportunity to develop new ways of thinking and behaving in both the mentee and the mentor. Mentoring can improve work performance, reinforce professional values and enhance surgeons' ability to deal with difficult situations and sensitive communications with patients and teams, all contributing to better patient care over the course of a career. ${ }^{4}$

The GDC Literature review on CPD has several references to mentoring, including:

'The modern concept of mentoring presumes that the mentor facilitates the mentee in the process of self-assessment and planning of learning activities, through interaction and feedback. Thus, mentoring promotes learning by facilitating the sharing of experience and expertise. $^{5}$

It is therefore hard to deny the groundswell of support for mentoring and the recognition of the benefits that mentoring can bring to professionals.

\section{Required skills}

Mentoring requires two things: having skill, expertise and experience that others find valuable; and having the ability and skills to mentor. Most dental professionals acquire skill, expertise and experience, this comes with time and undertaking tasks with competence and confidence. However, not all dental professionals have the ability or inclination to 
mentor. That requires a particular set of skills that do not always come naturally to all. For these skills I am a firm believer that training is needed. The skills I am writing about are set out in the following sections.

\section{Receptive listening with curiosity}

Mentors needs to demonstrate sincere curiosity about their mentees; questions should come from a place of curiosity rather than a place of knowing. Skilled mentors also listen beyond the words, they listen for data (information) and emotion. They listen to body language and they listen to what is not said. They listen for the little nuggets that tell them what the mentee is really saying; always there is true curiosity about the person. A skilled mentor makes no assumptions about what they are hearing. Receptive listening starts with an intention of hearing the real person: their values, their passion, their commitments, their unique talents and strengths, their answers and solutions. It is not listening with the sole intention of responding with pearls of wisdom.

\section{Questioning}

Mentors ask lots of open questions 'what...?', 'how...?', 'when....?', then listen. This is the time for the mentee to come up with possibilities. Asking questions challenges the mentee's thinking, especially if they seem stuck in one perspective. The 'why' question is used sparingly. It can often seem rather accusatory, although tone is important here too.

\section{Reflecting back}

Mentors accept what the mentee is offering; this might be facts, opinions or beliefs. They blend what is offered with a new possibility (yes and...) and, working together, something new is created. This helps to move the mentee forward to new opportunities.

\section{Building rapport}

A skilled mentor builds rapport with everyone and knows how important that is to relationships.
Showing rapport includes being $100 \%$ in the here and now. It means giving the person you are talking with your full attention. That may seem easy, however it is not. Being present and not distracted is a skill.

\section{Empathy}

An empathic mentor easily grasps the other person's perspective and they have an ability to get along well with people from diverse backgrounds or from different cultures. They have a good understanding of emotional and cultural intelligence.

\section{'Being' a mentor}

Of course, mentoring takes time. You have to set aside precious time to take off whatever hat you happen to be wearing and put on your mentoring hat. You have to carve out time and what will you stop doing to start mentoring? If I had a $£ 1$ for every time I hear someone say this, I would be able to fund a small country for a year. Why? Because I think we are all missing the point.

Many people may be thinking about mentoring as if it's something you are doing or not doing. If you are doing it, then you must carve out precious time to do it. For example, an educational supervisor may feel that they have to set time aside to mentor their foundation trainee. Perhaps this takes place at a specific time each week, this is the time they are 'mentoring'. The danger here is that by considering mentoring as additional to everyday routine then it is logical to feel there is no time to add something extra.

I would like to suggest that we should be thinking about mentoring as how we are 'being'. If we become mentors and practise the skills at all times, then we cease to 'do' mentoring as something out of the ordinary and find that we 'are' mentors. It is part of our character, our being and our regular behaviour. If a dental professional is being a mentor, this means using the skills of a mentor at all times. It's about using those skills during your professional life in all your encounters. That means mentoring your patients, your staff and your colleagues. When you are being a mentor and using those skills as part of your everyday routine then you don't need to find the time, you just are.

I need to be clear that there are times when it is appropriate and necessary to set aside specific time for mentoring. An example here is when mentoring someone for a very particular aspect, perhaps remediation or career planning. Educational supervisors are required to set aside specific time to support their trainees. Some dental professionals mentor as part of their career portfolio, for which they will be paid by their mentees. Clearly, in these instances, specific time is set aside.

\section{Conclusion}

In conclusion, I'd like to encourage all dental professionals not to view mentoring as something that needs to be an add on, something extra and therefore something that must always be funded. If we can move away from 'doing' mentoring to 'being' mentors, we will all gain and all parts of our professional life can be enriched.

\section{References}

1. General Dental Council. Shifting the balance: a better, fairer $x$ of dental regulation. 2019. Available at https:// www.gdc-uk.org/about/what-we-do/shifting-thebalance (accessed July 2019).

2. General Dental Council. Enhanced CPD guidance. 2018. Available at https://www.gdc-uk.org/api/files/ECPDguidance-for-professionals.pdf (accessed July 2019).

3. Royal College of Surgeons. Mentoring, a guide to good practice. 2018. Available at https://www.rcseng.ac.uk/-/ media/files/rcs/standards-and-research/standardsand-policy/good-practice-guides/new-docs-may-2019/ rcs-_mentoring.pdf (accessed July 2019).

4. University of Winchester. Evaluation of Remediation Support in UK Dentistry. 2015. Available at https://www. gdc-uk.org/api/files/Evaluation\%20of\%20Remediation $\% 20$ Support\%20in\%20Dentistry\%20report\%20FINAL\%20 May\%202015.pdf (accessed July 2019).

5. Association for Dental Education in Europe. A Review of the Literature on Continuing Professional Development. 2019. Available at https://www.gdc-uk.org/api/files/181205\%20 Full\%20Report\%20Review\%20of\%20the \%20 Literature\%20on\%20CPD.pdf (accessed July 2019). 